\title{
Familial Risk of Asthma for Children with Affected Family Members in Multiple Generations
}

\author{
Hong Yao Yu ${ }^{1}$, Qi-Hua Guan ${ }^{2}$, Kari Hemminki ${ }^{3}$, Shyamali Dharmage ${ }^{4}$, Gayan Bowatte ${ }^{5}$, \\ Dinh Bui ${ }^{4}$, Xiao-Wen Zeng ${ }^{1}$, Gong-Bo Chen ${ }^{6}$, Li Wen $\mathrm{Hu}^{1}$, Bo-Yi Yang ${ }^{1}$, Zi-Mian Liang ${ }^{2}$, \\ and Guang-Hui Dong ${ }^{7}$ \\ ${ }^{1}$ Sun Yat-Sen University \\ ${ }^{2}$ Foshan Center for Disease Control and Prevention \\ ${ }^{3}$ German Cancer Research Center \\ ${ }^{4}$ The University of Melbourne \\ ${ }^{5}$ The University of Melbourne School of Population and Global Health \\ ${ }^{6}$ Sun Yat-Sen University School of Public Health \\ ${ }^{7}$ Sun Yat-sen University
}

July 22, 2020

\begin{abstract}
Background: While a parental history of asthma has been widely reported as a risk factor for childhood asthma, less is known about the impact of multigenerational family history of asthma on the occurrence of asthma in children. Methods: From 2012 to 2013, a cross-sectional study was carried out in seven Chinese cities. Participants were randomly selected from 94 middle schools, elementary schools and kindergartens. Questionnaires, from which information on asthma, environmental exposure and family members (parents, paternal grandparents and maternal grandparents) affected by asthma were obtained, were completed by the children's parents or guardians. Two-level logistic regressions were used to assess hereditary patterns of asthma, adjusted for potential confounding factors. Mediation analysis was performed to estimate the potential mediation effect of parents on the association between grandparental asthma and offspring asthma. Results: A paternal grandfather (OR: 2.59, 95\%CI: 2.14-3.13), paternal grandmother (OR: 2.40, 95\%CI: 1.93-2.99), maternal grandfather (OR: 2.08, 95\%CI: 1.71-2.53) and maternal grandmother (OR: 2.08, 95\%CI: 1.67-2.59) with asthma were associated with childhood asthma, independent of parental asthma. Of the children who had two family members with asthma, the risk of childhood asthma was highest when both parents had asthma (OR: 15.92, 95\% CI: 4.66-54.45) or when both father and paternal grandfather had asthma (OR: 11.11, 95\%CI: 5.77-21.38). Parents had a small proportion of mediation effect on the association between grandparental asthma and childhood asthma. Conclusions: A family history of grandparental asthma was associated with childhood asthma and parents only partially mediate the association.
\end{abstract}

\section{INTRODUCTION}

Asthma is the most common non-communicable diseases among children, characterized by shortness of breath, rapid breathing, chest tightness and wheezing. ${ }^{1,2}$ The prevalence of childhood asthma has increased worldwide. Asthma is one of top reasons why children miss school days and visit emergency department, and it can affect children's long-term health by impairing lung function and increasing risk of developing Chronic Obstructive Pulmonary Disease (COPD). ${ }^{3}$ The etiology of asthma is not fully understood. Thus, identifying risk factors for childhood asthma could be beneficial to increase early detection of the disease and prevent adverse outcomes later in life. 
Asthma can be genetically heritable and the heritability estimated by twin studies ranges from $35 \%$ to $70 \% .{ }^{4}$ Although, genome-wide research has identified a number of asthma susceptibility loci, they only account for a small fraction of the heritability. ${ }^{5,6}$ There are still genetic risk factors waiting to be unveiled. A family history could provide useful information for gene susceptibility, if shared environmental factors were controlled. ${ }^{7}$ Parents with asthma has been widely reported to contribute to increasing offspring's asthma risk. ${ }^{8,9}$ However, the relative roles of maternal asthma and paternal asthma on their offspring's asthma risk is controversial. Some studies found that a maternal had stronger impact than a paternal, whereas others had the opposite findings. ${ }^{10}$ In addition, grandparents are relatives who share $25 \%$ of a person's genes. ${ }^{11}$ Rare studies have reported the impact of a grandparental on a child's risk of developing asthma.

In this study, we aimed to investigate the multi-generational hereditary patterns of asthma. We estimated the familial risks of asthma for children who had family members (parents, maternal grandparents and paternal grandparents) affected by asthma after controlling for potential environmental risk factors (e.g. environment tobacco exposure, ambient air pollution and pet keeping). ${ }^{12-14}$ In addition, we also estimated the impact of parents on the association between grandparental asthma and childhood asthma.

\section{METHODS}

\section{Study cities and participants}

Selection of the study cities and participants has been described previously in detail. ${ }^{15}$ In short, the crosssectional study was conducted in 27 districts of seven northeast cities in China from 2012 to 2013, including six districts in Shenyang, three districts in Anshan, three districts in Benxi, five districts in Dalian, three districts in Dandong, four districts in Fushun and three districts in Liaoyang. In each district, one or two kindergartens, primary schools and middle schools were randomly chosen. In each grade of the selected school, one class was randomly chosen and all the students in the class were enrolled. Totally, we obtained 68,647 participants aged from 0 to 20 years.

This study was carried out in accordance with the World Medical Association Declaration of Helsinki Ethical Principles for Medical Research Involving Human Subjects. The Human Studies Committee of Sun Yatsen University approved the study protocol and all the parents or guardians of the participants signed the informed consent before starting data collection.

\section{Study Questionnaire}

The information on doctor diagnosed asthma among participants was collected by the Chinese version of Epidemiologic Standardization Project Questionnaire of the American Thoracic Society (ATS-DLD-78-A), which were completed by parents or guardians. Doctor diagnosed asthma was defined by the question "Has a doctor ever diagnosed this child with asthma?" In addition, asthma for family members was also collected by the questions "Has this child's father ever had asthma?", "Has this child's mother ever had asthma?", "Has this child's paternal grandfather ever had asthma?", "Has this child's paternal grandmother ever had asthma?", "Has this child's maternal grandfather ever had asthma?" and "Has this child's maternal grandmother ever had asthma?". According to the total number of family members affected by asthma, participants were classified into four groups, no family member affected, 1 family member affected, 2 family members affected and [?] 3 family members affected.

\section{Covariates and mediator}

Information on covariates was obtained from the questionnaire, including age $(<5$ years, 5 - 10 years, $10-15$ years and [?]15 years), gender (boy/girl), exercise time (hours/week), family income per year ( $<10,000 \mathrm{RMB}$, 10,000-29,999RMB, 30,000-99,999RMB, or [?]100,000RMB), parental education ([?] high school or lower), low birth weight (birth weight $<2500 \mathrm{~g}$ ), premature birth (gestational age $<37$ ), breastfeeding (child being mainly breastfed for at least three months), obesity (yes/no), passive smoke exposure (child living with someone of the household who smokes daily at residence), home coal use (yes/no) and pet kept (yes/no), particulate matter with aerodynamic diameters $<2.5 \mu \mathrm{m}\left(\mathrm{PM}_{2.5}\right)$ exposure $\left(<48.97 \mu \mathrm{g} / \mathrm{m}^{3}, 48.97-56.23 \mu \mathrm{g} / \mathrm{m}^{3}, 56.23\right.$ $60.57 \mu \mathrm{g} / \mathrm{m}^{3}$, or [?]60.57 $\left.\mu \mathrm{g} / \mathrm{m}^{3}\right)$. The assessment of personal $\mathrm{PM}_{2.5}$ exposure has previously been described 
in detail. ${ }^{15,16}$ In brief, the average $\mathrm{PM}_{2.5}$ concentration during 2009-2012, estimated according to each participant's residence using a machine learning method, was regarded as a surrogate of individual exposure. Participants were categorized into four groups based on quartiles of $\mathrm{PM}_{2.5}$ concentration they were exposed. A directed acyclic graph (DAG) was drawn by online DAGitty (http://dagitty.net/dags.html) (Fig. S1). Variables, containing passive smoke exposure, home coal use, pet kept and $\mathrm{PM}_{2.5}$ exposure, were identified as potential confounders that needed adjusting in the main model. In addition, parent with asthma was identified as a potential mediator.

\section{Statistical analysis}

In the main model, a 2-level logistic regression was employed to estimate associations of different family history types with childhood asthma. Children were considered as the first level and studied districts were the second level. The reference group was participants who had no family member affected asthma. Odds ratios (ORs) and its 95\% confidence intervals (CIs) were calculated after adjusting for covariates. Mediation effects of parents between grandparental asthma and childhood asthma were estimated using $\mathrm{R}$ package mediation and 95\%CIs were estimated using quasi-Bayesian approximation (100 simulations). All statistical tests were two-tailed. $P<0.05$ was considered statistically significant in the study. Data analyses were conducted using $\mathrm{R}$ version 3.6.3. The computation was fulfilled in the high-performance computer system in the School of Public Health, Sun Yat-sen University.

\section{RESULTS}

In this study, a total of 59,484 children's parents or guardians completed questionnaires, and the response rate was $86.5 \%$. The average age of participants was 10.23 years, and $49.39 \%$ was girls (Table 1 ). The prevalence of childhood asthma was $7.77 \%$. Of those 4619 participants diagnosed with asthma, 585 cases $(12.67 \%)$ had one family member affected by asthma, 73 cases $(1.58 \%)$ had two affected family members and 13 cases $(0.28 \%)$ had at least three affected family members.

Fig. 1 shows the adjusted ORs for childhood asthma by the number of family members affected by asthma. The ORs were 2.58 (95\%CI: 2.34-2.84), 4.63 (95\%CI: 3.53-6.08) and 7.38 (95\%CI: 3.70-14.73) when one, two and at least three family members were affected, and the trend was statistically significant $(P<0.001)$. The crude ORs which are shown in Table S1 were slightly greater than those adjusted.

Among children with one family member affected by asthma, those with affected father had the highest adjusted OR (4.89, 95\% CI: 3.72-6.42, Cases: 75), followed by those with affected mother (OR: 3.94, 95\%CI: 2.99-5.20, Cases: 67), paternal grandfather (OR: 2.59, 95\%CI: 2.14-3.13, Cases: 132), maternal grandfather (OR: 2.40, 95\%CI: 1.93-2.99, Cases: 97), paternal grandmother (OR: 2.08, 95\%CI: 1.71-2.53, Cases: 119) and maternal grandmother (OR: 2.08, 95\%CI: 1.67-2.59, Cases: 95) (Fig. 2). The P value of the trend was statistically significant $(P<0.001)$. The corresponding crude ORs are shown in Table S2.

Among children with two family member affected by asthma, the odds of asthma for children's both parents were affected (OR: 15.92, 95\%CI: 4.66-54.45, Cases: 5) or those whose father and paternal grandfather were affected (OR: 11.11, 95\%CI: 5.77-21.38, Cases: 16) were higher than those with other family history types, including paternal grandparents affected (OR: 5.04, 95\%CI: 2.45-10.37, Cases: 10), maternal grandparents affected (OR: 4.39, 95\%CI: 1.88-10.27, Cases: 7), father and paternal grandmother affected (OR: 3.64, 95\%CI: 1.35-9.83, Cases: 5), mother and maternal grandfather affected (OR=5.54, 95\%CI: 1.46-21.07, Cases: 3), or mother and maternal grandmother affected ( $\mathrm{OR}=6.72,95 \% \mathrm{CI}$ : 2.86-15.81, Cases: 8) (Fig. 3). The crude ORs shown in Table S3 were slightly higher than those adjusted.

Table 2 shows the proportion of the effect of grandparental asthma on their grandchildren's asthma that was mediated by parental asthma. Paternal asthma significantly mediated the association of childhood asthma with paternal grandfather asthma (12\%) and paternal grandmother asthma (11\%), and maternal asthma significantly mediated the association of childhood asthma with maternal grandfather asthma (6\%) and maternal grandmother asthma $(9 \%)$.

\section{DISCUSSION}


We found that, a family history of asthma could increase the childhood asthma risk and the magnitude of ORs increased by the number of affected family members. Independent of having a parent with asthma, a paternal grandparent or a maternal grandparent with asthma could increase the risk for children to develop asthma. Children with father and parental grandfather affected by asthma $(\mathrm{OR}=11.11)$ had less asthma risk than those with parents affected $(\mathrm{OR}=15.92)$, but they had higher risk than those with two other family members affected by asthma. In addition, we also identified parents partially mediated the associations between grandparental asthma and childhood asthma.

By combining family history of parents and grandparents affected by asthma, we observed that the magnitude of ORs for childhood asthma increased by the number of affected family members and the trend was statistically significant, suggesting that a combined family history could be used as a tool to predict the potential risk for a child to develop asthma. A family history of parent affected by asthma has been widely reported to increase asthma risk. A review of 33 studies found that the ORs of asthma for children with the father affected by asthma ranged from 1.5 to 7.2 , and for those with mother affected ORs ranged from 1.5 to $9.7 .{ }^{10}$ In our study, the ORs for a family history of father and mother were 4.89 and 3.94 , which fell within the range.

It remains controversial whether paternal or maternal asthma have more impact on the development of childhood asthma. In our study, we observed children who had father affected by asthma were at greater risk than those with mother affected. We also observed although the ORs of asthma for those having a father and paternal grandfather with asthma were less than those having parents with asthma $(\mathrm{OR}=11.11$ vs $\mathrm{OR}=15.92$ ), they were much higher than those who had two other family members with asthma, suggesting that inheritance of asthma tend to be paternal link. The underlying biological mechanism is poorly understood. However, studies have identified that a family history of paternal asthma was associated with airway hyperresponsiveness (AHR) in children with asthma, whereas a family history of maternal asthma was not. ${ }^{17,18}$ Since AHR is a major character of asthma, it is speculated that genetic risk factors for AHR that passed down from father's side might contribute to childhood asthma. ${ }^{18}$

A family history of second-degree relatives has been proved to be a risk factor for many diseases ${ }^{19,20}$, but studies investigating the impact of second-degree relatives on the development of childhood asthma are limited. A study on Utah population found that a family history of second-degree relatives who died of asthma could increase the risk of asthma mortality by $34 \%$ (95\% CI: 9-62\%). ${ }^{21}$ A previous study reported that, among 823 children diagnosed with asthma, $69.8 \%$ had a family history of asthma, of which $14.2 \%$ had an affected grandmother, $6.5 \%$ had an affected grandfather and $3.3 \%$ had both affected grandparents. ${ }^{22}$ Valerio et al, who investigated the intergenerational asthma, found that a family history of grandparental asthma was associated with childhood asthma $(\mathrm{OR}=1.52)$ and children with a parent and grandparent affected by asthma were over four times more at risk of developing asthma compared to those with no parent and grandparent affected $(\mathrm{OR}=4.27) .{ }^{23}$ These studies did not consider lineage (paternal grandparents or maternal grandparents) which have different influence on certain diseases. ${ }^{24,25}$ In our study, based on the sufficiently large sample, we were able to distinguish grandparents between paternal and maternal lineage. Our results showed that a family history on either a paternal grandparent or a maternal grandparent with asthma was associated with an increased risk of childhood asthma, independent of parental asthma, although the impact on the asthma risk was less than a family history of a parent. This suggested that shared asthma susceptibility genes play a small role in transgenerational inheritance. Furthermore, our results of mediation analysis, which showed the small proportion of mediation effect of parental asthma, supported this evidence. Asthma is a complex disease, and the interaction of gene-gene and gene-environment which influences the asthma susceptibility may lead to the transgenerational inheritance of asthma from grandparents to grandchildren with parents skipping over.

In our study, we recruited a large number of participants, which allowed us to differentiate paternal and maternal grandparents and investigate the associations between the family history of a grandparent with asthma and asthma risk in grandchildren. Environmental factors are confounders for family history used to predict the hereditary patterns of a disease ${ }^{7}$. In this study we controlled a series of environmental factors 
associated with asthma, especially $\mathrm{PM}_{2.5}$, a major ambient air pollution in recent years in China. Our study, however, has several limitations. The information of both childhood asthma and their family history of asthma was from self-reported questionnaires, but not from the hospital discharge registries, which may cause the recall bias and misclassification of a family history. Since the one child-policy in China, the family history of sibling, which is an important genetic risk factor for hereditary disease, were unable to evaluated.

\section{CONCLUSIONS}

In this study, we found that the childhood asthma risk increased by the number of family members affected by asthma. A family history of a grandparent with asthma was associated with childhood asthma and the association was only partially mediated by parent with asthma. In addition, children who had father and parental grandfather with asthma had similar magnitude of asthma risk with those who have both parents with asthma. Our findings could be used to identify children at high risk for asthma in early childhood.

Table 1. Characteristics of participants.

\begin{tabular}{|c|c|c|c|c|c|}
\hline Variables & $\begin{array}{l}\text { Total } \\
(\mathrm{n}=59,484)\end{array}$ & Asthma & Asthma & Asthma & $P$-valu \\
\hline & & $\begin{array}{l}\text { Yes } \\
(\mathrm{n}=4,619)\end{array}$ & & No & \\
\hline$(n=54,865)$ & $\mathbf{N} \%$ & $\mathbf{N} \%$ & & N \% & \\
\hline $\begin{array}{l}\text { Age (years } \\
{[\text { mean }} \\
(\mathrm{SD})])^{*}\end{array}$ & $10.23(3.92)$ & $9.50(3.82)$ & & $10.29(3.92)$ & $<0.001$ \\
\hline$<5$ years & $5647(0.09)$ & $480(0.10)$ & & $5167(0.09)$ & \\
\hline $5-10$ years & $\begin{array}{l}18171 \\
(0.31)\end{array}$ & $1778(0.38)$ & & $\begin{array}{l}16393 \\
(0.30)\end{array}$ & \\
\hline 10-15 years & $\begin{array}{l}28000 \\
(0.47)\end{array}$ & $1954(0.42)$ & & $\begin{array}{l}26046 \\
(0.47)\end{array}$ & \\
\hline [?]15 years & $7666(0.13)$ & $407(0.08)$ & & $7259(0.13)$ & \\
\hline $\begin{array}{l}\text { BMI } \\
\left(\mathrm{kg} / \mathrm{m}^{2}\right. \\
{[\text { mean }} \\
(\mathrm{SD})])^{*}\end{array}$ & $18.57(4.47)$ & $18.71(4.63)$ & & $18.56(4.46)$ & 0.037 \\
\hline $\begin{array}{l}\text { Exercise } \\
\text { time per } \\
\text { week } \\
\text { (hours } \\
{[\text { mean }} \\
(\mathrm{SD})])^{*}\end{array}$ & $6.56(7.96)$ & $6.15(7.64)$ & & $6.59(8.00)$ & $<0.001$ \\
\hline Gender & & & & & $<0.001$ \\
\hline Boys & $\begin{array}{l}30,105 \\
(50.61)\end{array}$ & $\begin{array}{l}2,845 \\
(61.59)\end{array}$ & & $\begin{array}{l}27,260 \\
(49.69)\end{array}$ & \\
\hline Girls & $\begin{array}{l}29,379 \\
(49.39)\end{array}$ & $\begin{array}{l}1,774 \\
(38.41)\end{array}$ & & $\begin{array}{l}27,605 \\
(50.31)\end{array}$ & \\
\hline $\begin{array}{l}\text { Asthma } \\
\text { family } \\
\text { history } \\
*\end{array}$ & & & & & $<0.001$ \\
\hline
\end{tabular}




\begin{tabular}{|c|c|c|c|c|c|}
\hline Variables & $\begin{array}{l}\text { Total } \\
(\mathrm{n}=59,484)\end{array}$ & Asthma & Asthma & Asthma & $P$-valu \\
\hline $\begin{array}{l}\text { No family } \\
\text { member } \\
\text { affected }\end{array}$ & $\begin{array}{l}55641 \\
(93.54)\end{array}$ & $\begin{array}{l}3948 \\
(85.47)\end{array}$ & & $\begin{array}{l}51693 \\
(94.22)\end{array}$ & \\
\hline $\begin{array}{l}1 \text { family } \\
\text { member } \\
\text { affected }\end{array}$ & $3529(5.93)$ & $585(12.67)$ & & $2944(5.37)$ & \\
\hline $\begin{array}{l}2 \text { family } \\
\text { members } \\
\text { affected }\end{array}$ & $279(0.47)$ & $73(1.58)$ & & $206(0.38)$ & \\
\hline $\begin{array}{l}\text { [?] } 3 \text { family } \\
\text { members } \\
\text { affected }\end{array}$ & $35(0.06)$ & $13(0.28)$ & & $22(0.04)$ & \\
\hline
\end{tabular}

${ }^{*} p<0.05$ for difference between children with asthma and non-asthma children using t-test or chi-square test.

Abbreviations: RMB, Chinese Yuan.

Table 2. Mediation effect of parental asthma between grandparental asthma and childhood asthma.

\begin{tabular}{lllll}
\hline Independent variable & Mediator & Proportion mediated & 95\%CI & $P$-value \\
\hline Paternal grandfather & Father & $12 \%$ & $8-16 \%$ & $<0.001$ \\
Paternal grandmother & Father & $11 \%$ & $7-18 \%$ & $<0.001$ \\
Maternal grandfather & Mother & $6 \%$ & $3-9 \%$ & $<0.001$ \\
Maternal grandmother & Mother & $9 \%$ & $5-14 \%$ & $<0.001$ \\
\hline
\end{tabular}

Abbreviation: CI, confidence interval.

\section{Hosted file}

image1.emf available at https://authorea.com/users/345068/articles/471418-familial-risk-ofasthma-for-children-with-affected-family-members-in-multiple-generations

Fig. 1. Adjusted ORs and $95 \%$ CIs for childhood asthma by the number of family members affected by asthma compared to those without any family member affected.

Adjusted for passive smoke exposure, home coal use, pet kept and $\mathrm{PM}_{2.5}$ exposure.

\section{Hosted file}

image2.emf available at https://authorea.com/users/345068/articles/471418-familial-risk-ofasthma-for-children-with-affected-family-members-in-multiple-generations

Fig. 2. Adjusted ORs and $95 \%$ CIs for asthma among children with one family member affected by asthma compared to those without any family member affected.

Adjusted for passive smoke exposure, home coal use, pet kept and $\mathrm{PM}_{2.5}$ exposure.

\section{Hosted file}

image3.emf available at https://authorea.com/users/345068/articles/471418-familial-risk-ofasthma-for-children-with-affected-family-members-in-multiple-generations 
Fig. 3. Adjusted ORs and $95 \%$ CIs for asthma among children with two family members affected by asthma compared to those without any family member affected.

Adjusted for passive smoke exposure, home coal use, pet kept and $\mathrm{PM}_{2.5}$ exposure.

\section{REFERENCES}

1. Papi A, Brightling C, Pedersen SE, Reddel HK. Asthma. Lancet (London, England) 2018; 391 (10122): 783-800.

2. Beasley R, Semprini A, Mitchell EA. Risk factors for asthma: is prevention possible? Lancet (London, England) 2015;386 (9998): 1075-85.

3. Dharmage SC PJ, Custovic A. Epidemiology of Asthma in Children and Adults. Frontiers in pediatrics 2019; 7 (246).

4. Morales E, Duffy D. Genetics and Gene-Environment Interactions in Childhood and Adult Onset Asthma. Front Pediatr 2019; 7 : 499.

5. Han Y, Jia Q, Jahani PS, et al. Genome-wide analysis highlights contribution of immune system pathways to the genetic architecture of asthma. Nature communications 2020; 11 (1): 1776.

6. Pividori M, Schoettler N, Nicolae DL, Ober C, Im HK. Shared and distinct genetic risk factors for childhood-onset and adult-onset asthma: genome-wide and transcriptome-wide studies. The Lancet Respiratory medicine 2019; 7 (6): 509-22.

7. Hemminki K, Li X, Sundquist K, Sundquist J. Familial risks for common diseases: etiologic clues and guidance to gene identification. Mutation research 2008; 658 (3): 247-58.

8. Paaso EM, Jaakkola MS, Lajunen TK, Hugg TT, Jaakkola JJ. The importance of family history in asthma during the first 27 years of life. American journal of respiratory and critical care medicine 2013; 188 (5): 624-6.

9. Paaso EM, Jaakkola MS, Rantala AK, Hugg TT, Jaakkola JJ. Allergic diseases and asthma in the family predict the persistence and onset-age of asthma: a prospective cohort study. Respiratory research 2014;15 (1): 152 .

10. Burke W, Fesinmeyer M, Reed K, Hampson L, Carlsten C. Family history as a predictor of asthma risk. American journal of preventive medicine 2003; 24 (2): 160-9.

11. Merikangas KR. Applied Computational Genomics: Springer Netherlands; 2012.18p.

12. Brooks JL, Asafu-Adjei J, Currin EG, Beeber LS. Exploring a broader context of the home environment and its relationship with asthma control in American Indian children. Research in nursing $\&$ health 2020;43 (3): 218-29.

13. Ayuk AC, Ramjith J, Zar HJ. Environmental risk factors for asthma in 13-14 year old African children. Pediatric pulmonology 2018;53 (11): 1475-84.

14. Davila Cordova JE, Tapia Aguirre V, Vasquez Apestegui V, et al. Association of $\operatorname{PM}(2.5)$ concentration with health center outpatient visits for respiratory diseases of children under 5 years old in Lima, Peru. Environmental health : a global access science source 2020;19 (1): 7.

15. Yang M, Chu C, Bloom MS, et al. Is smaller worse? New insights about associations of $\mathrm{PM}(1)$ and respiratory health in children and adolescents. Environment international 2018; 120 : 516-24.

16. Chen G, Li S, Knibbs LD, et al. A machine learning method to estimate $\operatorname{PM}(2.5)$ concentrations across China with remote sensing, meteorological and land use information. The Science of the total environment 2018; 636 : 52-60. 
17. Raby BA, Van Steen K, Celedón JC, Litonjua AA, Lange C, Weiss ST. Paternal history of asthma and airway responsiveness in children with asthma. American journal of respiratory and critical care medicine 2005; 172 (5): 552-8.

18. Ly NP, Soto-Quirós ME, Avila L, et al. Paternal asthma, mold exposure, and increased airway responsiveness among children with asthma in Costa Rica. Chest 2008; 133 (1): 107-14.

19. Cannon-Albright LA, Foster NL, Schliep K, et al. Relative risk for Alzheimer disease based on complete family history. Neurology2019; 92 (15): e1745-e53.

20. Frank C, Fallah M, Ji J, Sundquist J, Hemminki K. The population impact of familial cancer, a major cause of cancer. International journal of cancer 2014; 134 (8): 1899-906.

21. Teerlink CC, Hegewald MJ, Cannon-Albright LA. A genealogical assessment of heritable predisposition to asthma mortality. American journal of respiratory and critical care medicine 2007;176 (9): 865-70.

22. Sheikh SI, Pitts J, Ryan-Wenger NA, McCoy KS, Hayes D, Jr. Environmental exposures and family history of asthma. The Journal of asthma : official journal of the Association for the Care of Asthma2016; 53 (5): 465-70.

23. Valerio MA, Andreski PM, Schoeni RF, McGonagle KA. Examining the association between childhood asthma and parent and grandparent asthma status: implications for practice. Clinical pediatrics 2010;49 (6): $535-41$.

24. Lai Y, Qi J, Tao X, et al. Associations of grandparental diabetes mellitus with grandchild BMI status. BMC public health 2019;19 (1): 172.

25. Kinnally EL, Gonzalez MN, Capitanio JP. Paternal line effects of early experiences persist across three generations in rhesus macaques.Developmental psychobiology 2018; 60 (8): 879-88. 